\title{
Meal for Two: Creating Mood and Characterization Through Cinematography
}

\author{
Malvin Hernanta Betekeneng \\ English Department, Faculty of Languages and Literature, Petra Christian University, Siwalankerto 121- \\ 131, Surabaya 60236, INDONESIA \\ m11414016@john.petra.ac.id
}

\begin{abstract}
This creative work is about the cinematography report from the screenplay meal for two by Satrio Haryanto. The story tells about two neighbors, a man and a woman, who lives next door but they do not know about each other personally. The woman realizes that the man attracted to her but she prefers to keep her distance, but after sometime, they get together since both shares the same secret. This creative work aims to portray the mood in order to create suspense, distance and closeness and to show the man's paraphilia, the man's curiosity, and the woman's introversion. An in-depth analysis will be further developed to portray the mood. In order to support those elements, there are several techniques used such as low-key lighting, framing. These techniques are to help the cinematographer to convey the drama suspense genre. In addition, a detailed analysis will further explain different uses of camera work, lighting, and color in building the characterization in the whole movie. As a result, my work as a cinematographer will explain on how the mood and characterization on this film fits with the drama suspense genre.
\end{abstract}

Keywords: cinematography, low-key lighting, camerawork, color, framing.

\section{INTRODUCTION}

Cinematography is a one part of important pieces that made a movie, movie. Cinematography is more than just a photography, since it combines all elements such as action, tone, words, etc, to translate them into moving pictures (Brown, 2012). Cinematographer or known as director of photography, often work in the technical aspect of a movie such as choosing the lens, color, composition, etc. as long as it supports the story. It is a duty for a cinematographer too to build a world within the characters in the movie for the audience to understand. A cinematographer needs to convert the story as well as it could be because filmmaking is what the audience perceived both intellectually and emotionally (Brown, 2012). Working as a cinematographer, I have to work side by side with the director and translate his vision into visual of what he wanted and there were few steps before the shooting which is called the pre-production stage. There, we started by breaking down the script and discussed scene by scene of what the tone of the film would look like. During the production, I have to make sure all the camera work perfectly and the lighting were well maintained in the frame. In post-production, I need to involve in terms of how the color grading should look since it is part of the cinematographer job as how the final look should be. From what I have learned so far, both theory and practical skill, in which I also have my own short film as a cinematographer, I aim to combine all of my experiences to create a thesis project.

The film I was working for is called Meal for Two. It is about the relationship between a man and a woman who lives next to each other in a small apartment but they do not know about each other. The woman already has a boyfriend but their relationship is not working well while the man realizes that, and he tries to take the opportunity to get close to her. At one point, he learns that they have mutual connection which is they have killed a person before and based on that 
they decide to eat the human meat together. They start to become cannibals which eventually makes them start being together. This movie is fourteen minutes in term of length, and portraying the mood and characterization is the most important elements in this movie since the movie has only two lead characters. The director of this film wanted this movie to be slow paced since there is almost less action involved and did not want to confuse the audience with too many cuts and camera angles. He also wanted to have a deep contrast and shadows to shape a gloomy and dark feeling for the mood and tones of the film.

The film genre of the film is drama suspense. The genre consists of drama, which is the development of romance between two characters and a suspense where there is a surprising event that is hidden but eventually will exists later to surprise the audience. The suspense is based around the upcoming events and how it tells the events for the audience to notice. Drama suspense genre has been quite popular genre in the past few years, in terms of cinematography, this genre builds in different way to any other genre. The use of low-key lighting is the first part to get the audience. The way the lighting lights up the scene and shapes the characters' identity can affect the audience perspective about the film. Also, the use of different lenses and angles can tell different story with many options to the audience. For example, low angle shot can show superiority of a character to the other and the use of close up shot to show a character's emotional state.

In building the cinematography for this film, I decided to take several references from movies such as The Assassination of Jesse James by the Coward Robert Ford (2007), Gone Girl (2012) and se7en (1995). Looking at the criteria of what the director wants on how the film would look, the approach on cinematography would be on the camera work, color, and lighting objectives. These three main key features are important because the movie would walk around this medium. The main location is in a small old-fashioned apartment, and the scenes happen both interior and exterior and mostly on night time. For the mood and tone, it is important to make it gloomy and dark in order to tell the audience that something is not right at the beginning of the film. As for the camera work and color, I wanted to use it effectively according to the story. Another thing to describe is the characterization where each character is different, and in this cinematography, I planned to build the characterization based on the relationship between them and the action happens later on in the film.

\section{CONCEPT AND ANALYSIS OF THE CREATIVE WORK}

\subsection{Modes of Expression}

The short film genre is drama suspense with the subgenre of a crime. To create a cinematography for both characters, there are several things that I needed to consider. The relationship between both characters is a foundation to build a cinematography. First, is to create what mood and look fits the movie. This movie sets in an old-fashioned small pension house, looking at its genre that contains crime and suspense, it is good to make a low-key lighting that creates gloomy or dark tone. This tone will be throughout the movie to bring consistency for the audience to see. Second, judging by the characterization on the main actors, in which they are not close to each other, it is important to create a visual that separates them apart in terms of camerawork.

The main issue in this movie is about the development of the relationship between the main leading actor, Yeonggi, and the female leading actress, Minhee. Both shares the same dark secret in which they have killed someone before and eat their victims' mutilated body, or known as cannibalism. However, the main idea of this film is more on the relationship between the man and the woman. 
The decision that I made as a cinematographer depends on the development of the script. It is not only about the development on the characterization, but it can also be the development in terms of camerawork. The movie is about suspense and needs a gloomy tone, however if the gloomy time passes, in terms of lighting it can also be changed into a brighter tone. Since this film is about the journey between two characters becoming one, also will end in plot twist, I decided to use camerawork and lighting to portray all the situation the characters going through. In order to follow the development on the story, the camerawork as well as the lighting will follow the change on the character and the story. The relationship between the man and the woman, in the beginning, they are not close and the woman seems to be closing herself from the man. However, they start dating each other after some time. The shots on the camera focuses on their relationship as I used distance on the framing to portray them. In terms of the look, I used a gloomy tone to tell the foundation about their relationship or in this case the cannibalism.

\subsection{Genre Codes and Conventions}

In this section, I want to explain about the genre codes and conventions that I use for my creative work in meal for two. I will compare the characteristics of cinematography in suspense, romance movie and compare it to my short film. I retrieved these codes from Joyce G. Saricks' The Readers' Adivosry Guide to Genre Fiction.

\begin{tabular}{|l|l|l|}
\hline $\begin{array}{l}\text { Cinematography } \\
\text { Elements }\end{array}$ & $\begin{array}{l}\text { Genre } \\
\text { Convention of } \\
\text { Suspense }\end{array}$ & $\begin{array}{l}\text { Genre Convention } \\
\text { of my work }\end{array}$ \\
\hline Camera works & $\begin{array}{l}\text { Close up, Extreme } \\
\text { close up }\end{array}$ & $\begin{array}{l}\text { In my work, I use less camera movement since there } \\
\text { are almost no necessary action that need to use } \\
\text { camera movement and more into conversation } \\
\text { between characters. I decided to use reaction shot } \\
\text { because there are mainly two characters in the whole } \\
\text { scene. }\end{array}$ \\
\hline Color and tone & $\begin{array}{l}\text { Dark Color } \\
\text { Pallete, } \\
\text { Uneasiness }\end{array}$ & $\begin{array}{l}\text { My main color palette is analogous orange from the } \\
\text { tungsten lighting which will cast shadows and } \\
\text { contrast throughout the movie. It will also create a } \\
\text { tense and dark feeling for the audience to feel. }\end{array}$ \\
\hline Lighting & $\begin{array}{l}\text { Low Key Lighting, } \\
\text { Shadows during } \\
\text { nightime }\end{array}$ & $\begin{array}{l}\text { The mood and tone of the movie is dark, so low key } \\
\text { lighting is perfect since it create a lot of shadows and } \\
\text { leave a little room for the lighting. The practical } \\
\text { lightings that I used for this movie were Lumos 300 } \\
\text { mostly for fill lighting or ambience in the room, Arri } \\
\text { 650W also for room ambience since it can cast hard } \\
\text { shadow, Mole 2K for main lighting outside, Joker } \\
\text { 5600K, and Dedo Master for fill lighting. }\end{array}$ \\
\hline
\end{tabular}

\subsection{The Ways to Build Mood and Characterization Through Cinematography}

The fourteen minutes film is packed with drama, and suspense. As a cinematographer in this film, I need to visualized the script and formed it into well visual manner in the forms of camera work, lighting, as well as color. I aimed two things from the cinematography: to build the suspense of the story and to build the characterization. 


\subsubsection{Mood}

The first goal of the cinematography is to create mood for the audience to feel when they are watching the film. Mood can be created through the lighting and also camera work. Since this movie is about romance and suspense, the use of dark color pallete and low-key lighting is best to put in this movie to convey the overall mood and look.

\subsubsection{Creating Suspense}

I created suspense through lighting. The lighting that I used specifically was the low-key lighting. Low-key lighting is best to use because it can isolate the subject, convey a drama, and make the audience feel uneasy by creating contrast and shadow in the frame (Ward, 2015).

The suspense in this scene (Figure 1a) is where the robber comes in to the man's apartment room. I decided to place the stand light behind the actor because not only to act as a key lighting but also to act as a decoration to the room which makes a motivational lighting.

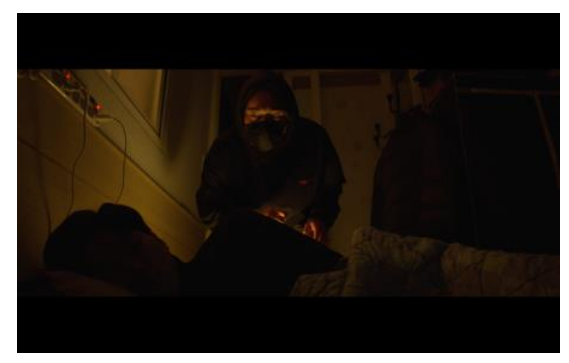

Figure 1a

The stand light holds an important role for the robber since it shines through him directly as a key lighting. As the robber walks up to the actor, it creates a cast of shadow on the wall behind the robber in which it will make the shadow bigger as he walks closer to the front. This will make the audience realize that the robber takes up the scene.

In this scene also (figure 1a), to create the power of the robber in terms of camerawork, I decided to use the low angle shot and on fix position. I decided to use a low angle shot because it can make the subject has more authority and power in the shot (StudioBinder, 2018). As seen in the picture, I wanted the audience to think that the robber position is higher than the man and it indicates that he holds more power over the man. Another thing to notice, I put the robber in the center of the framing because I wanted to put the robber as the main attention for the audience to see. The robber walks in towards the actor and the camera, and by doing that, as he walks slowly, he will make himself bigger as he walks step by step.

In figure $1 \mathrm{~b}$ and $1 \mathrm{c}, \mathrm{I}$ decided to trick the lighting in order to imitate the original lighting from the fridge where right after the man discover the woman's secret, he starts to show his'.

Since I wanted to show someone opens the fridge, I should create a lighting from dark to bright. There I used a card board, and then slowly open it as if it is a fridge door. The effect can be seen from figure $1 \mathrm{~b}$ and $1 \mathrm{c}$ where the was no lighting in the left image and suddenly a lighting shows up on the right image. In doing this, I wanted to show the audience that through the lighting that I already set up, and drive the audience so that they can feel what the woman is feeling right after the lighting hit her face. The lighting here also supported by the reaction of the woman who suddenly feels surprised. 


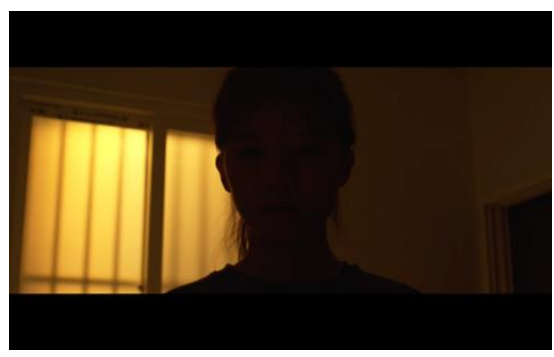

Figure $1 b$

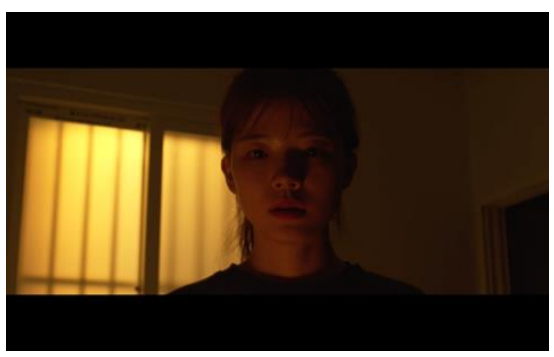

Figure 1c

In both shots, I used the close-up shot in low angle position in order to put the audience closer to her and could see her reaction better. In this shot particularly, I used the low angle shot not to show the woman's power but more into what is she looking at. The fridge is smaller than her and in order to create a realistic visual, I decided to go for that position. It is not a point of view (pov) shot since the eyeline of the woman is not directly into the camera position but rather below it.

\subsubsection{Characterization}

The second goal of the cinematography is to show the characterization. In describing the characterization, I aimed to show the paraphilic in the man, the man's curiosity, and the introverted woman.

\subsubsection{The Man's Paraphilia}

Paraphilia is a type of condition in where the person's sexual arousal or behavior that are distressing to others with the potential to harm (Brown, n.d, para. 1). One of the paraphilias type is called hybristophilia where an individual obtain pleasure from commit a crime such as robbery or murder (Griffiths, 2013). In this film, the man shows his' paraphilia as he kills the robber without any hesitation. I created the cinematography that is fit to show the man's paraphilia through lighting and framing.

First, the lighting technique that I used is low key lighting. This scene is important in order to show the man's paraphilic personality. In order to create the man's personality, I decided to dimmed the lighting. For the key light, I used the stand light besides the actor and for the fill I used the ambience light from 650k lighting from outside. The lighting from outside only fill a certain part of the room, while the main actor remains dark since he is also put his back behind the light. In figure $2 \mathrm{~b}$, as the actor steps forward, he becomes entire dark and I did that in order to support his personality to kill someone. The key light (stand light) is the most important part because when the actor sits next to the lamp, the lamp lit only his half face (figure 2a). The half face lighting or side lighting, not only makes him dramatic but also it shapes his paraphilic personality since the lighting that falls on him is half lighting that makes half of him is good and half is not. 


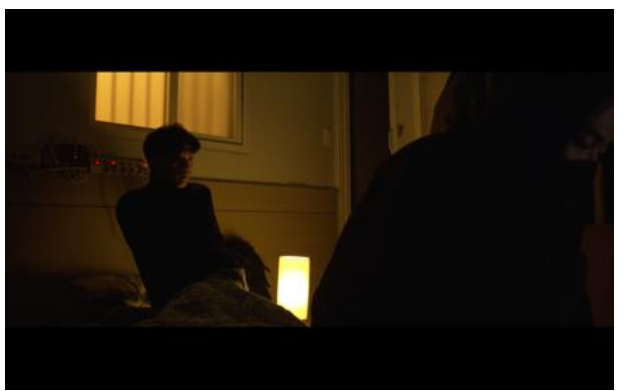

Figure 2a

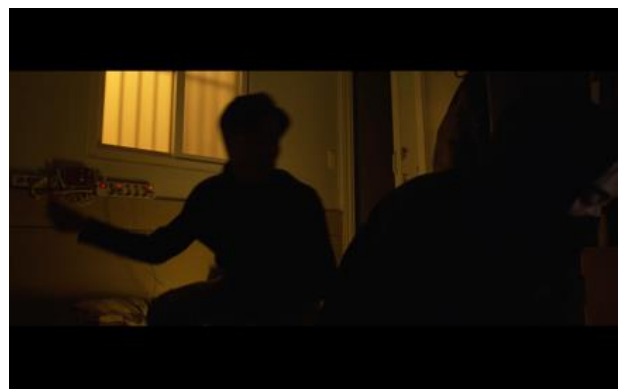

Figure $2 b$

Second, the framing that I used is from the rule of third and in a fixed position to show a single action within one frame. In Figure 2a, there is a distance between the man and the robber. The man looks small in the back while the robber fills half of the framing. In the figure $2 a$, the robber holds more power in the scene than the man. Seconds later, there is a shift of power from the robber to the man. In both frames, I used the low angle shot to show power. Here, the man does not think twice to kill the robber. By having that idea, I put the camera in one position only and let the man do all the action. This shows in figure $2 b$, the man stabs the robber in a higher position than the robber which shows now that the man holds the power in that scene. So, by put it in one shot, the man who was inferior (figure 2a), now controls the scene and shows his personality through the framing and lighting.

\subsubsection{The Man's Curiosity}

A curiosity is the recognition and desire in order to find and acquire new information as desired (Kashdan, 2018). As the man get attracted to the woman, he became more curious of the woman's life. I used the camerawork to show the man's curiosity to the woman's situation.

The man's curiosity already shown in the first scene (Picture 2c) as I used over the shoulder shot. In the framing, I put the boyfriend in the foreground takes half of the frame and the man in the background on one third only. I wanted to show the audience that the man is watching the argument and have no power to interfere. Another note, to show that the man does not want to involve in this situation, I put a little gap between him and the boyfriend.

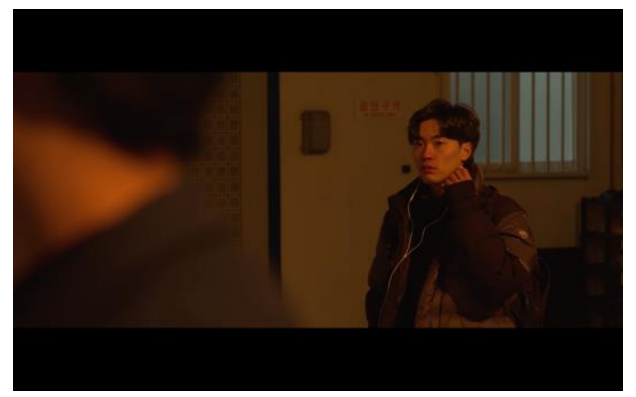

Figure 2c

In picture $2 \mathrm{~d}$, the man is curious about the sound of someone crying coming from the other room in the middle of the night. I used tight medium close up shot to show something important is happening in the scene. The shot starts with the close up shot of the man's shoulder (figure $2 \mathrm{~d}$ ) then as he walks up, the frame gets wider (figure 2e). The shot starts at close up in order to get the audience attention as the man realize something at that point. The shot is on shallow depth of field and only focus at the man at first. As he walks towards the wall, the audience also 
follow him to see what happen at this scene. By putting the camera still, I want to involve the audience in emotional involvement because the way the frame centered on the man's reaction.

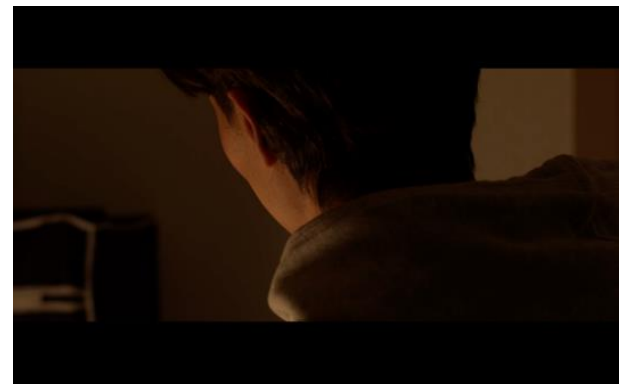

Figure 2d

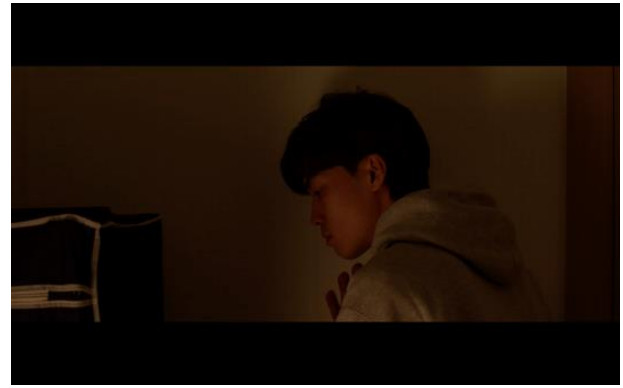

Figure 2e

\subsubsection{The Introverted Woman}

Introversion is a character trait that centered on themselves rather than on external sources of stimulation (Cherry, 2019). The woman from the beginning of the film keep herself closed from the man who tries to get to know her. To portray the introvert woman, I used framing and medium close up shot in the camerawork.

First, I decided to use the framing in order to show her introversion. In this scene (figure $2 \mathrm{f}$ ), the man asks her if she wants to have dinner together, but she rejects. The scene is in exterior, so I decided to use the medium shot on wide angle lens because it gives a wide field of view in the framing. In this shot, the woman stands alone and I wanted to show the audience that by using wide field of view, it is like trapping the woman in a wide world. In results, it can give the feeling that she is alone, also the closed body position of her give more sense that she is introvert person.

Next, I used the medium close up shot to show that the woman is feeling uncomfortable when she is alone in the shot, which show that she is introverted. Still in the same scene, the shot changes from over the shoulder to medium close up shot (figure $2 \mathrm{~g}$ ). Here, the woman reacts to the man's question in doubt or in uncertain response. I used the medium close up because I want to show the audience about her reaction in a closer look and how empty the frame is. In the frame, there is only her and the other thing in the frame is not moving instead of her. The emptiness inside the frame gives the woman a lot of space. I wanted to show the audience that by using the wide frame, the reaction of the woman becomes clearer since she does not want to get close to the man.

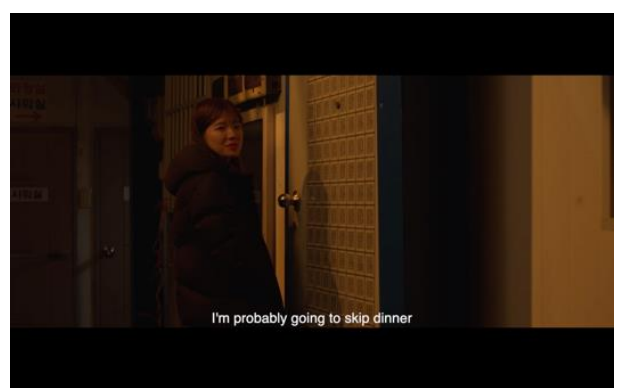

Figure 2f

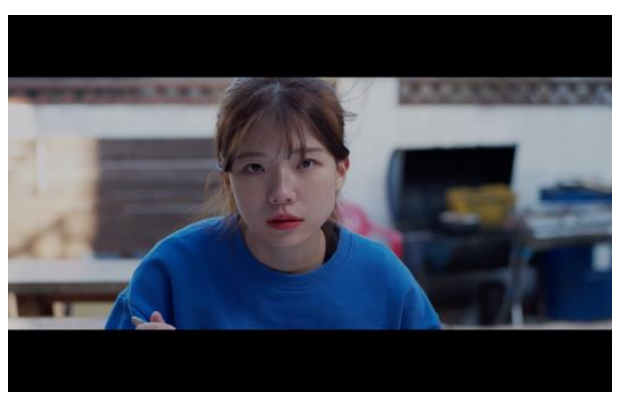

Figure $2 g$ 


\section{CONCLUSION}

I built my cinematography through mood and characterization in support of the drama and suspense genre. To convey the story into visual, the choices on lenses, framing, lighting, and color are key aspects to determine the final results of the film. Cinematography is one of the important elements in the film since it connect the film with the audience, doing it randomly the audience might lose their interest. Therefore, cinematography needs to be crafted in details, make sense, and serve the story perfectly.

There are valuable lessons that I learned upon making this short film as a cinematographer from the pre-production until the post-production. First of all, I learnt to work both under pressure and on limited time. Second, I learned with people from different backgrounds and have different opinion. All in all, there were things in the shooting process that we could not control. However, as an individual or working in a crew, we needed to minimize unnecessary things in order to get things done perfectly. Also, it is better to take more time on the scene in order to get the shot desired rather than rushed things out and the final results is not as expected.

Indonesia film industry is still on its way to bigger potential. However, there is still a limited number of genres in Indonesia and not every genre can fit here since there is a different culture between the west and the east. In a bigger picture, I want to work outside the country to develop my skills since the movie genre in Indonesia is still limited compared to the west. Later, whenever possible in the future, I would like to share my knowledge to younger generation so that they can be inspired and put more interest into filmmaking or creative industry. Filmmaking is fun since film can inspire people, so I want to inspire the audience and younger generation to be involved in the making.

Working as a cinematographer is not as easy as it looks since we responsible on the final look of the movie. Cinematographer job not only limited on how cool or amazing the shot looks like but also, we also have to make sure that everything we decide serve a purpose to the film. Starting from the choices of lenses such as normal lens, fix lens, etc. and on why we choose the lens, until the lighting that we need to shape for each type of genre. It is important for cinematographer to tell the story well so it is not confusing the audience who watch the movie.

\section{REFERENCES}

Brown, B. (2012). Cinematography: theory and practice ( $2^{\text {nd }}$ ed). Waltham, MA: Elsevier.

Brown, G.R. (n.d). Overview of paraphilic disorders. Retrieved May 23, 2019, from https://www.premiumbeat.com/blog/cinematic-shot-reverse-shot/

Cherry, K. (2019). 8 signs you're an introvert. Retrieved May 9, 2019, from https://www.verywellmind.com/signs-you-are-an-introvert-2795427

Griffiths, M.D. (2013). Passion victim, a brief look at hybristophilia. Retrieved May 19, 2019, from https://www.psychologytoday.com/intl/blog/in-excess/201310/passion-victim

Kashdan, T.B. (2018). What are the five dimensions of curiosity? Retrieved April 25, 2019 , from https://www.psychologytoday.com/us/blog/curious/201801/what-are-the-fivedimensions-curiosity

Saricks, J.G. (2009). The readers' advisory to genre fiction ( $2^{\text {nd }}$ ed). Library of Congress.

StudioBinder. (2019). Low angle shot: creative examples of camera movement \& angles. Retrieved April 4, 2019, from https://www.studiobinder.com/blog/low-angle-shotcamera-movement-angle/\#low-angle-shot-effect

Ward. C. (2015). How low key lighting can instantly make your film dramatic. Retrieved January 14, 2019, from https://www.premiumbeat.com/blog/how-low-key-lighting-caninstantly-make-your-film-dramatic/ 